\title{
E-Learning Based on Cloud Computing
}

\author{
https://doi.org/10.3991/ijet.v16i10.18579 \\ Wei Wu $\left({ }^{\bowtie}\right)$ \\ Wuxi Institute of Technology, WuXi, China \\ ipxplay@outlook.com \\ Anastasiia Plakhtii \\ Prydniprovska State Academy of Civil Engineering and Architecture, \\ Dnipro, Ukraine
}

\begin{abstract}
Modern technological paradigms of learning give educators an ability to support the development of highly professional human resources. For this reason, teachers of higher educational institutions find advanced technologies more and more useful. Rapid introduction of cloud computing into pedagogical practice creates a professional need to study the technological capabilities of cloud-based learning services to select the best educational solutions among available variants. In view of this, the current article provides a theoretical overview of e-learning cloud architecture layers and models of its deployment in the education system. In order to test the adaptability of learning management systems (LMSs) to a collaborative distance learning model, research among educators of I.M. Sechenov First Moscow State Medical University (Russia), Prydniprovska State Academy of Civil Engineering and Architecture (Ukraine) and Wuxi Institute of Technology (China) was carried out using the Blackboard Learn LMS as a case study. This study involved 100 individuals who tested the Blackboard Learn teaching capabilities. The conducted investigation allowed outlining the main advantages of the use of computer-based e-learning applications in the process of organizing and supporting the educational process. Among them are convenient means of processing educational content, effective educational process organization, effective tools for knowledge monitoring, and effective security and confidentiality system. The present work also shed light on the benefits of introducing cloud-based e-learning in higher educational institutions, as producers of an integrated educational product. The study confirmed that the introduction of cloud computing in education results in the advancement of the training content and can considerably improve students' academic results due to updated learning technologies, concepts, and tools.
\end{abstract}

Keywords-Cloud computing, e-learning, distance education, cloud computing architecture 


\section{Introduction}

In modern society, proper education is vital for business and socio-economic growth [1]. The pervasive adoption of various Internet services, especially social networks, has increased the digital literacy of the world population. Therefore, modern technological paradigms of learning, such as mobile learning, are becoming more popular [2]. Worldwide trends in the digital economy development have resulted in further technological complexity and disappearance of many traditional professions owing to the automation of human actions and the emergence of new personnel requirements. Now, the virtual environment covers a large portion of labor relations and even segments of employment. As a consequence, the formation of new competencies and restructuring of the whole education system becomes necessary [3].

With the rapid rise in popularity of the Internet in educational practices, curriculum delivery has moved from local desktops to online applications. Recent technological advances have led universities to introduce innovative educational methods. New technologies provide higher education institutions with many interesting tools that can be used to improve the educational process [4]. The widespread use of technology, constantly updated information, the need for students to access information everywhere and the personalization of education have led to the emergence of distance learning, e-learning and mobile learning. Wireless technologies and mobile devices play an important role in popularizing these concepts [5].

A significant trend in universities has been the introduction of so-called Learning Management Systems (LMS), which are used as a common platform on which students and teachers can interact digitally [6]. LMS not only provides academic institutions with effective learning tools, but also enables the efficient organization and sharing of academic knowledge [4].

Cloud computing is among the emerging technological innovations that can dramatically influence the education by applying dynamic scalability and resource efficiency. The cloud-based e-learning model has a scale efficiency mechanism that transfers the role of constructing the e-learning system to cloud computing vendors. This gives providers and users the possibility to build an advantageous relationship. For education, such a model becomes an instrument that can save a considerable share of expenses for providing an innovative educational process. Partnerships and costeffectiveness continue to be a privilege of cloud-based e-learning because educational institutions are responsible only for the learning process, content management, and knowledge delivery, while the vendor deals with construction, maintenance, development, and management of the educational system. The cloud-based environment can run on a wide range of hardware devices and support the creation of nextgeneration e-learning systems. Modern users do not require any special knowledge about cloud computing to connect their PCs or laptops to the server [7]

The National Institute of Standards and Technology (NIST) defines cloud computing as a model for providing networked access on demand to servers, network storage, applications or services that are delivered with minimal management effort and interactions with service providers [8]. Cloud computing enables moving the processing work from the local devices to data centers. The software is referred to as a service. The applications and data are stored on various servers that can be accessed through any device connected. The transparency of the cloud infrastructure provides a 
user-centric interface. Applications are placed in scalable data centers where computing resources can be dynamically allocated and shared to achieve a meaningful economy of the needed scale [9]. The use of cloud services can lead to huge cost savings when purchasing and maintaining technical infrastructure and software (servers, data transmission lines, uninterruptible power supplies), lower the need of computer maintenance specialists, solve technical problems, and eliminate troubles in the engineering [10].

Cloud computing provides a unique possibility to expand the availability of education. Along with the emergence and application of advanced technologies, cloud computing provides an excellent opportunity to develop e-learning. Today, students and teachers can get a prompt access to numerous application platforms and webbased educational resources through the Internet. An educational institution does not need to worry about creating a software and hardware environment for online education or investing considerable amounts of money and human and material resources in designing an e-learning system. All these functions can be outsourced to e-learning cloud service providers. The cloud-based e-learning model provides a high level of data security through distribution of data storage, centralized management and visualization of the data service [11].

Various educational organizations are expanding the presence of e-learning in educational practices. Since the e-learning system usually requires the purposeful use of networked technologies in educational processes, cloud computing is an excellent alternative for academic institutions that have less funds to host and operate their online learning systems. The benefits of cloud computing in education, especially in e-learning, are attracting the attention of many developers and software vendors [12].

Recently, many colleges, universities, and even schools are applying cloud-based e-learning applications in their educational process. However, many of them apply them as support to their main learning management systems (LMS) [13]. The introduction of cloud computing into higher educational institutions' pedagogical practice creates a professional need to study the technological capabilities of cloud services in order to select optimal educational solutions among analogs. In this regard, the present research was aimed at testing the adaptability of cloud computing applications for e-learning and identifying the benefits of using systems in ensuring a quality educational process. The achievement of this goal was possible after the solution of the following tasks:

- Perform a theoretical review of the layers of e-learning cloud architecture and models of its deployment in the educational segment.

- Test the capabilities of the Blackboard Learn cloud platform for providing interactive e-learning, creating online communities and sharing knowledge in a virtual environment.

- Analyze the adaptability of the Blackboard Learn for the collaborative distance learning model.

- Identify the main advantages of using the Blackboard Learn in the training process and during its organization.

- Identify benefits from the introduction of computer-based e-learning for higher educational institutions, as producers of an integrated educational product. 


\section{Methods}

In this day and age, cloud computing has become the predominant technology that can propose unlimited computing for different social or business applications [14]. At the present stage of the educational segment development, cloud computing technologies are cost-effective services that enable the generation of the learning quality [15]. E-learning cloud represents a shift of innovative cloud computing technology to the elearning area, which thereby forms educational infrastructure with all the necessary hardware and software computing resources [7].

E-learning cloud architecture can be conventionally divided into several layers. Infrastructure layer of e-learning is located in the lowest level of cloud service middleware and consists of information infrastructure and teaching resources. Information infrastructure includes system software, information management system, and universal software and hardware. Educational resources are formed from training materials developed in the traditional teaching model and are distributed throughout the educational structure. Through the use of the cloud-based e-learning model, physical server, storage, and network form a virtualization group - a pool of physical hosts. Software resource layer is formed by the operating system and middleware. Here, a variety of software resources are integrated to provide a unified interface for e-learning software developers. Specialized applications are developed based on software resources and embedded in the cloud, making them available for users. Resource management layer is the key to achieve the interaction between software and hardware resources. Service layer has three levels of cloud computing services defined as SaaS (Software as a Service), PaaS (Platform as a Service), IaaS (Infrastructure as a Service).

\subsection{SaaS (Software as a Service)}

SaaS is a software licensing and delivery model that provides software products to customers by request [16]. Its services are hosted by a cloud computing provider and are composed of software applications [17]. SaaS delivers such services as e-mail, conferencing software, and various business applications like Enterprise Resource Planning, Customer Relationship Management, and Supply Chain Management [18]. A single application is run on the server-side, accessed by one or more runs on the cloud services and multiple end-users or client organizations. The most widely known SaaS examples are salesforce.com, Google Apps, Dropbox, MailChimp, ZenDesk, DocuSign, Slack, Hubspot [19]. SaaS is also considered a basic service model used to access the software through the cloud [20]. Artificial intelligence (AI) in SaaS is represented in the form of machine learning (ML), which is involved in Machine-ToHuman workflows [21]. The presence of AI in SaaS takes the form of hyperpersonalization. It represents custom educational content that emerged after the user collaborated with ML [22].

Cloud computing users do not affect the quality, integrity, and availability of data. They have to rely on security measures adopted by cloud providers [23]. Thus, cloud service vendors' reputation mainly depends on the fulfillment of the Service Level Agreement, which they perform during operational activities. To provide the best 
services, large organizations have a propensity to take multiple cloud application services, which is called the Hazy Cloud process. As a result of these actions, cloud service vendors are forced to lock their services sometimes, and users should simultaneously move from one service to another. In any case, access to services is always supplemented by the advent of vendor-user relationships, and both should try to improve mutual security [19]. SaaS platforms provide a limited approach at the client end, making the server end much resourceful. In such a manner, it provides minimal integrated control for service-based functionality to end-users of the client [24].

\subsection{PaaS (Platform as a Service)}

PaaS offers the consumer an electronic environment for deploying cloud infrastructure using platform-level and software-level resources such as operating systems and application platforms. PaaS services are mainly used because of less optimal solutions or results of IaaS or due to the specifications of the involved in the network IT applications [25]. In PaaS, AI acts as an accelerator in relationships between the ecosystem and the user [26].

\subsection{IaaS (Infrastructure as a Service)}

In IaaS cloud service vendor shares a pay-as-you-go facility to access the several features of network servers, computational applications, and storage over the Internet [27]. IaaS is an architecture that balances the number of resources allocated to service with actual users' needs. For this reason, IaaS uses a load balancer, PHP, and MySQL servers [28].

In the early stages of building a cloud architecture, cloud services were offered only in three fundamental modes, i.e., SaaS, PaaS, and IaaS. Though, later emerged such domain-specific services as BPaaS - business process as a service [29]. In BPaaS, the role of $\mathrm{AI}$ is connected with the relationship between Education 4.0 and Cloud-based e-learning [28].

The last one, application layer, operates based on applications that integrate educational resources into the cloud-computing model and facilitate the development of interactive courses and distribution of learning resources. This process consists of content development and delivery, educational goals' formation, and knowledge assessment and management. Distribution of educational resources includes teaching material and information resources in digital libraries and information centers [7] (Fig. 1). 


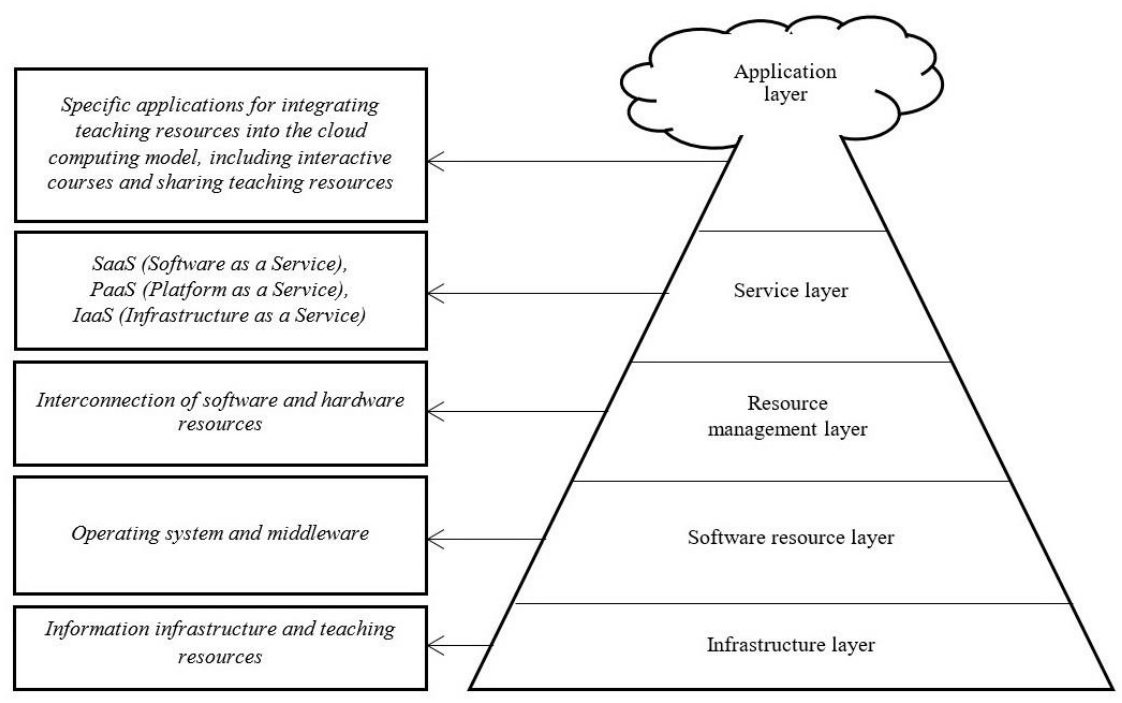

Fig. 1. E-learning cloud architecture

*Developed by the authors based on [7]

There are four common examples of cloud deployment models. All of them are presented in Fig. 2.

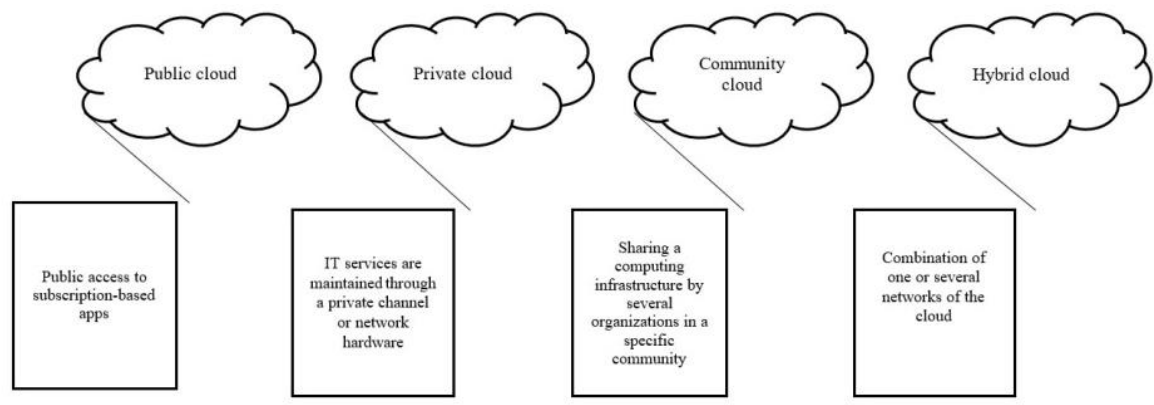

Fig. 2. Cloud deployment models

*Developed by the authors based on [19]

Cloud-based e-learning provides user-centric adaptive hardware resources, computing environment, and software services. In the cloud, users can access digital services transparently at any time and from any place [9]. Often e-learning cloud systems take into account the requirements of educational institutions concerning training resources' virtualization, centralized data storage, low operating costs, scalability, flexibility, and e-learning systems' availability. Therefore, the cloud-based e-learning architecture includes the cloud management system, hardware and software computing resources and services offered by the cloud [22,30]. 
Most software vendors present their services on cloud platforms. Blackboard Learning - is one of the brightest examples of cloud-based LMSs that deliver online education services. In a similar vein, open-source e-learning solutions are also hosted on various cloud platforms like MoodleCloud [2].

Since the introduction of advanced technologies and training standards based on learning management systems (LMS) can provide a qualitatively new level of distance learning organization, in 2019-2020, among educators of I.M. Sechenov First Moscow State Medical University (Russia), Prydniprovska State Academy of Civil Engineering and Architecture (Ukraine) and Wuxi Institute of Technology (China) experimental study was carried out. The goal of this investigation was to test the adaptability of LMSs to a collaborative distance learning model on the example of Blackboard LMS. For this purpose, the study involved 100 educators who were required to examine the capabilities of Blackboard Learn in the teaching process.

\section{$3 \quad$ Results and Discussion}

Blackboard Learn is an open, cloud-based education platform focused on improving the learning experience by providing online training opportunities in synchronous and asynchronous environments. In a synchronous environment, students and teachers are given the ability to interact in real time. A famous example of a synchronous tool is Blackboard Collaborate, where one can organize study sessions, have impromptu discussions, and host guest speakers. In an asynchronous environment, students can take advantage of the hourly generated schedule of reminders about upcoming events [31].

Blackboard Learn proposes learners to undergo three types of courses: fully online, hybrid or blended, and a traditional with added web components (Fig. 3).

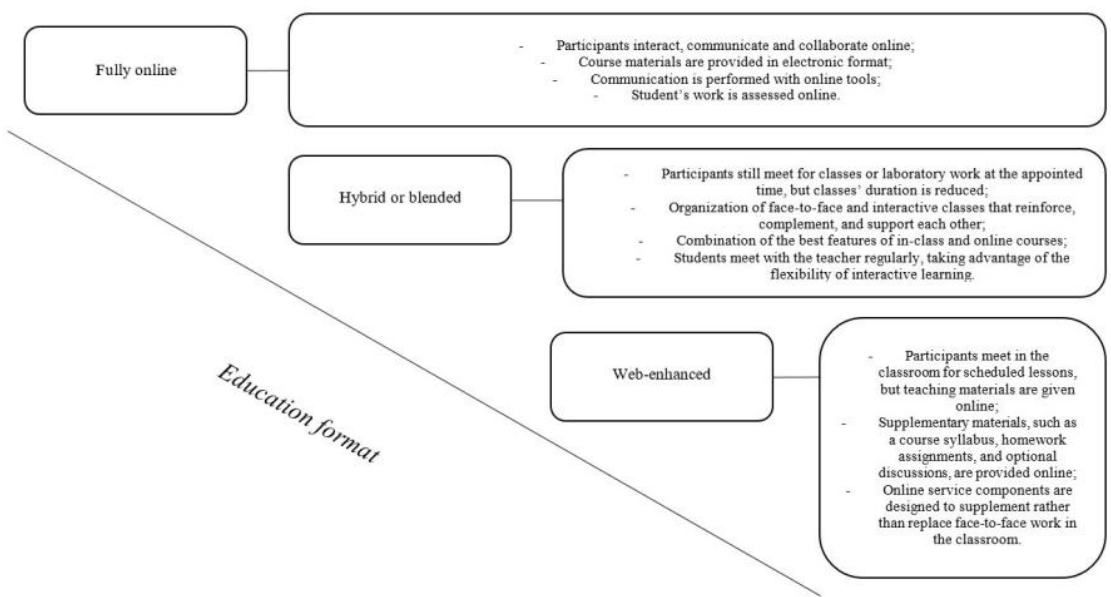

Fig. 3. Types of online courses in Blackboard Learn

*Developed by the authors based on [32] 
Using the Blackboard learning platform, students can check on course changes, complete assignments and tests, participate in discussions, launch collaborative sessions, and view grades. The Blackboard Instructor mobile app allows teachers to view the course content, grade assignments, undergo discussions with students, and work with their student groups [31].

The conducted research on approbation of e-learning based on the Blackboard Learn platform revealed the following central advantages of its use in the process of organization and provision of the educational process:

Convenient means of processing educational content: Blackboard Learn allows using ready-made educational course design templates, adding and editing text documents of any format, embedding formulas in any part of the text, uploading personal and YouTube videos, and supports all modern image file formats, as well as flash.

Effective educational process organization: This distance learning system has no restrictions concerning its use in various courses. It provides the possibility of group communication via video chat, student forums, shared calendars, text chats, boards, etc. In addition, learning management algorithms of Blackboard Learn can be edited and, by setting specific parameters and sequences of courses, one can create an automatic management system.

Effective tools for knowledge monitoring: Blackboard Learn provides catalogs of individual and group test items and course questions. It enables tailoring the learning course to a particular student by collecting statistics on a variety of conducted tests. Furthermore, Blackboard Learn has a built-in tool for checking educational work for plagiarism.

Effective security and confidentiality system: Blackboard Learn has a password system, and each user must log in to the system to access the course.

The introduction of cloud-based e-learning provides the following advantages for a higher education institution as a producer of an integrated educational product [33]:

- Users can run applications with a minimum internet connection configuration.

- Absence of performance-related issues in the process of functioning of users' computers (or mobile devices) since the prevailing part of applications and processes are reserved in the cloud.

- Automatical update of the software.

- Compatibility with different file and font formats.

- Benefits for learners - the entire learning process is online, including taking courses, passing exams, getting feedback from teachers, as well as assigning and receiving projects and tasks.

- Benefits for educators - methodological support of the educational process is carried out online (preparation of tests; composition of course material; management of the learning content; assessment of completed tests, homework, and projects; sending feedback to students; and communication with learners on the forums).

Higher educational institutions should adopt digital technologies in teaching and learning to enable learners to acquire digital competence necessary to stimulate innovation and employment. The educational process management in universities and colleges should include the use of advanced interactive teaching methods based on 
innovative digital software [3]. A more adaptive knowledge management system based on cloud services, if implemented, contributes to the improvement of education quality. Apart from this, the application of cloud computing technologies is relevant for the realization of the lifelong learning principle [15]. However, given the rapid and global deployment of next-generation mobile networks $(4 \mathrm{G}, 5 \mathrm{G}, 6 \mathrm{G})$, the popularity of cloud computing in the educational segment will be enhanced.

Even though e-learning is based on innovative digital technologies, it will not replace traditional teaching methods. At the same time, it can significantly increase the effectiveness of education through the application of advanced technologies, concepts, and tools that provide new content, models, and teaching methods. The main advantages of using cloud servers in the educational process include powerful computing capabilities, high-capacity data storage, virtualization, and high availability and security of cloud services. The cloud-based e-learning architecture provides powerful computing power and a huge data storage space by locating the computing and data in a large number of distributed computers. In the cloud computing model, administrators ensure the security of user data and, to the greatest extent possible, manage unified data, allocate resources, balance load, deploy the software, and do the reliable real-time monitoring [7].

Currently, due to lower enrollment rates and less physical presence of students in classes, various colleges and universities give the possibility to undergo certain courses in a distance mode. Research on the adaptability of cloud-based e-learning in Malaysian universities has revealed that the decision to implement this model is mainly influenced by the need and perceived usefulness of the technology. In the meantime, innovation is not significant in the intention to implement cloud-based e-learning Cloud computing has become appealing to many educational institutions because it has numerous benefits, in particular, geographic distribution and effective cost allocation related to automated systems and open-source software. The systemic communication between learners and teachers in different geographic settings enables the creation of lively and interactive learning platforms, allows active group work, and implements more effective teaching methods [33].

Despite the rapid introduction of cloud technologies in university educational practices, there are concerns about whether these technologies are used as effective teaching tools or simply as a repository of electronic documents [6,34]. Results from various researchers indicate that although many university staff around the world use LMS to varying degrees, the vast majority cannot take advantage of the potential pedagogical benefits offered by the full functionality of the software [6].

The cloud computing paradigm has revolutionized the computer science horizon and has attracted significant attention from academia, industry, and government agencies. Recent technological developments such as the Internet of Things, Serverless Computing, Software-Defined Networking, and edge processing have created new opportunities for cloud computing and formed the basis for the development of the digital economy. However, they have also created a need for new research strategies to reevaluate and improve approaches to scalability, elasticity, reliability, security and resilience [35]. 
With the introduction of cloud computing technology in higher education, a number of challenges connected with security, privacy, inadequate professionalism, and slow Internet connection emerge. According to a study carried out in Bangladesh [36], several key factors that drastically influenced the introduction of cloud computing at the University of Dhaka are lack of adequate infrastructure, service availability, and utility in education. Studies of the prospects for the use of cloud computing in higher education in Sudan also raise the issue of privacy and security [37].

The decision to introduce cloud computing into university practice is related not only to technological readiness but also to cultural aspects. Research towards a comparison between the Middle East and Europe in terms of the implementation of cloud computing into the educational process has explicated that European nations have a higher tendency to adopt advanced technologies, while the Middle East still prefer traditional ways of learning. As regards security issues that are yet to be solved, Europe already has special centers for this aim, while Middle Eastern countries, particularly Oman and Qatar, are still dealing with security problems. In addition to that, cloud-based education in the Middle East is only going through its initial phase, while many European universities are actively introducing advanced educational technologies [38]. The decision to implement cloud-based e-learning in a particular country is influenced by several important factors. Among them are perceived usefulness, ease of use, trust, security, need, and intention to study in such a mode [11].

\section{Conclusion}

Modern technological paradigms of learning are becoming more and more popular among teachers of higher educational institutions, whose activities are aimed at training highly professional personnel of the digital age. Cloud computing has a significant impact on the teaching and learning environment by leveraging dynamic scalability and resource efficiency, thereby expanding the boundaries of educational opportunities and ensuring the availability of educational services. The introduction of advanced technologies and training standards based on cloud computing establishes a new level of distance education organization. The present work provides a theoretical overview of the e-learning cloud architecture layers and models of its deployment in the education segment. In order to test the adaptability of LMSs to a collaborative distance learning model, in 2019-2020, among educators of I.M. Sechenov First Moscow State Medical University (Russia), Prydniprovska State Academy of Civil Engineering and Architecture (Ukraine) and Wuxi Institute of Technology (China) experimental study was carried out using the Blackboard Learn application for interactive e-learning, creation of online communities, and virtual knowledge exchange. This research enrolled 100 educators who were supposed to test the teaching capabilities of the Blackboard LMS. Within the investigation, the main advantages of the use of Blackboard Learn in the process of organizing and supporting the educational process were outlined, namely, convenient means of processing educational content, effective educational process organization, effective tools for knowledge monitoring, and effective security and confidentiality system. Furthermore, the current article presented the 
advantages of introducing cloud-based e-learning in higher educational institutions. The study proves that the introduction of cloud computing into the educational process leads to positive changes in the quality of the educational content and can considerably increase the efficiency of training due to updated learning technologies, concepts, and tools that render new teaching content, models, and methods.

\subsection{Scientific value}

Demonstrated cloud computing architecture and cloud deployment models expand the scientific understanding of the e-learning paradigm based on cloud-based technology solutions.

\subsection{Practical value}

The implemented innovative solutions in the operational activities of educational institutions affect the quality component of the integrated educational product, thereby providing of its competitive advantage. Since cloud computing forms the basis of the modern educational paradigm, the results of testing the Blackboard Learn platform open up new horizons for technological modernization and improvement of educational practice, being professionally interesting for the teaching and management staff of modern universities.

\subsection{Research limitations}

The Blackboard Learn cloud platform was tested only in the direction of exploring the benefits of the system in the context of educational content creation and educational practice tooling. Which is insufficient to assess the impact of using the platform on the quality of the educational process. Evaluation of the quality of e-learning based on cloud platforms requires studying the student's experience of interacting with the educational resource, teacher and study group in the context of the platform organization of the educational process. Therefore, the study has demonstrated only the advantages of cloud solutions in the provision of the educational process in order to identify progressive innovative opportunities to improve the educational experience.

\section{$5 \quad$ References}

[1] Nguyen, T.D., Nguyen, D.T., Cao, T.H. (2014). Acceptance and use of information system: E-learning based on cloud computing in Vietnam. In Information and Communication Technology-EurAsia Conference. Springer, Berlin, Heidelberg, pp. 139-149. https://doi. org/10.1007/978-3-642-55032-4_14

[2] Ahmad, N., Hoda, N., Alahmari, F. (2020) Developing a Cloud-Based Mobile Learning Adoption Model to Promote Sustainable Education. Sustainability, 12: 3126. https://doi. org/10.3390/su12083126

[3] Korepin, V.N., Dorozhkin, E.M., Mikhaylova, A.V., Davydova, N.N. (2020). Digital Economy and Digital Logistics as New Area of Study in Higher Education. International 
Journal of Emerging Technologies in Learning, 15(13): 137-154. https://doi.org/10.39 91/ijet.v15i13.14885

[4] Papadakis, S., Kalogiannakis, M., Sifaki, E., Vidakis, N. (2017). Access moodle using smart mobile phones. A case study in a Greek University. In Interactivity, Game Creation, Design, Learning, and Innovation. Springer, Cham, pp. 376-385. https://doi.org/10.1007/ 978-3-319-76908-0 36

[5] Talan, T. (2020). The effect of mobile learning on learning performance: A meta-analysis study. Educational Sciences: Theory and Practice, 20(1): 79-103. https://doi.org/10.12 738/jestp.2020.1.006

[6] Papadakis, S., Kalogiannakis, M., Sifaki, E., Vidakis, N. (2018). Evaluating Moodle use via Smart Mobile Phones. A case study in a Greekn University. EAI Endorsed Transactions on Creative Technologies, 5(16): 1-9. https://doi.org/10.4108/eai.10-4-2018.156382

[7] Masud, M.A.H., Huang, X. (2012). An e-learning system architecture based on cloud computing. System, 10(11): 255-259.

[8] Mell, P., Grance, T. (2011). The NIST definition of cloud computing. National Institute of Standards and Technology.

[9] Shirzad, M., Ahmadipour, M., Hoseinpanah, A., Rahimi, H. (2012). E-learning based on cloud computing. In 2012 International Conference on Cloud Computing Technologies, Applications and Management (ICCCTAM). IEEE, pp. 214-218. https://doi.org/10.1109/ iccctam.2012.6488101

[10] Chandra, D.G., Borah, M.D. (2012). Cost benefit analysis of cloud computing in education. In 2012 International Conference on Computing, Communication and Applications. IEEE, pp. 1-6. https://doi.org/10.1109/iccca.2012.6179142

[11] Shahzad, N., Ismail, A., Golamdin, A.G. (2016). Opportunity and Challenges using the Cloud Computing in the Case of Malaysian Higher Education Institutions, International Journal of Management Science and Information Technology, 20(20): 1-18.

[12] Siddiqui, S.T., Alam, S., Khan, Z.A., Gupta, A. (2019). Cloud-based e-learning: Using cloud computing platform for an effective e-learning. In Smart Innovations in Communication and Computational Sciences. Springer, Singapore, pp. 335-346. https://doi.org/10. $\underline{1007 / 978-981-13-2414-7 \quad 31}$

[13] Moravčík, M., Segeč, P., Uramová, Y., Kontšek, M. (2017). Teaching cloud computing in cloud computing. In Conference: 2017 15th International Conference on Emerging eLearning Technologies and Applications (ICETA). IEEE, pp. 1-6. https://doi.org/10.1109/iceta. $\underline{2017.8102512}$

[14] Naveed, Q.N., Ahmad, N. (2019). Critical Success Factors (CSFs) for Cloud-based ELearning. International Journal of Emerging Technologies in Learning, 14(01): 140-149. https://doi.org/10.3991/ijet.v14i01.9170

[15] Liu, Z.-Q., Dorozhkin, E., Davydova, N., Sadovnikova, N. (2020) Effectiveness of the Partial Implementation of a Cloud-Based Knowledge Management System. International Journal of Emerging Technologies in Learning, 15(13): 155-171. https://doi.org/10.3991/ ijet.v15i13.14919

[16] Joshi, N., Shah, S. (2019). A comprehensive survey of services provided by prevalent cloud computing environments. In Smart Intelligent Computing and Applications. Springer, Singapore, pp. 413-424. https://doi.org/10.1007/978-981-13-1921-1_41

[17] Colman-Meixner, C., Develder, C., Tornatore, M., Mukherjee, B. (2016). A survey on resiliency techniques in cloud computing infrastructures and applications. IEEE Communications Surveys \& Tutorials, 18(3): 2244-2281. https://doi.org/10.1109/comst.2016.253 $\underline{1104}$ 
[18] Giannakis, M., Spanaki, K., Dubey, R. (2019). A cloud-based supply chain management system: effects on supply chain responsiveness. Journal of Enterprise Information Management, 32(4): 585-607. https://doi.org/10.1108/jeim-05-2018-0106

[19] Nazir, R., Ahmed, Z., Ahmad, Z., Shaikh, N.N., Laghari, A.A., Kumar, K. (2020). Cloud Computing Applications: A Review. EAI Endorsed Transactions on Cloud Systems, 6(17): 5. https://doi.org/10.4108/eai.22-5-2020.164667

[20] Li, Y., Xia, S., Cao, B., Liu, Q. (2019). Lyapunov optimization-based trade-off policy for mobile cloud offloading in heterogeneous wireless networks. IEEE Transactions on Cloud Computing, pp. 1-3. https://doi.org/10.1109/tcc.2019.2938504

[21] Galletta, A., Carnevale, L., Celesti, A., Fazio, M., Villari, M. (2017). A Cloud-Based System for Improving Retention Marketing Loyalty Programs in Industry 4.0: A Study on Big Data Storage Implications. IEEE Access, 6(c): 5485-5492. https://doi.org/10.1109/access. 2017.2776400

[22] Hendradi, P., Khanapi, M., Mahfuzah, S.M. (2019). Cloud Computing-Based E-Learning System Architecture in Education 4.0. In Journal of Physics: Conference Series. IOP Publishing, Vol. 1196, No. 1, p. 012038. https://doi.org/10.1088/1742-6596/1196/1/012038

[23] Tchernykh, A., Schwiegelsohn, U., Talbi, E.G., Babenko, M. (2019). Towards understanding uncertainty in cloud computing with risks of confidentiality, integrity, and availability. Journal of Computational Science, 36: 100581. https://doi.org/10.1016/j.jocs.2016.11.011

[24] Kumar, S., Vajpayee, A. (2016). A survey on secure cloud: security and privacy in cloud computing. American Journal of Systems and Software, 4(1): 14-26.

[25] Zaballos, A.G., Rodríguez, E.I. (2018). Cloud Computing: Opportunities and Challenges for Sustainable Economic Development in Latin America and the Caribbean. InterAmerican Development Bank. https://doi.org/10.18235/0001083

[26] Lee, K. (2018). AI Platform to Accelerate API Economy and Ecosystem. Harvard Business Review 2012: 848-852.

[27] Stephen, A., Benedict, S., Kumar, R.A. (2019). Monitoring IaaS using various cloud monitors. Cluster Computing, 22(5): 12459-12471. https://doi.org/10.1007/s10586-017-1657-y

[28] Hendradi, P., Abd Ghani, M.K., Mahfuzah, S.N., Yudatama, U., Prabowo, N.A., Widyanto, R A. (2020). Artificial Intelligence Influence in Education 4.0 To Architecture Cloud Based E-Learning System. International Journal of Artificial Intelligence Research, 4(1): 1-9. https://doi.org/10.29099/ijair.v4i1.109

[29] Ahmad, N. (2017). Cloud computing: Technology, security issues and solutions. In Proceedings of the $20172^{\text {nd }}$ International Conference on Anti-Cyber Crimes (ICACC), Abha, Saudi Arabia; pp. 30-35. https://doi.org/10.1109/anti-cybercrime.2017.7905258

[30] El Mhouti, A., Erradi, M., Nasseh, A. (2018). Using Cloud Computing Services in ELearning Process: Benefits and Challenges. Education and Information Technologies, 23(2): 893-909. https://doi.org/10.1007/s10639-017-9642-x

[31] Blackboard (2018). Blackboard Product Help. https://help.blackboard.com/

[32] Blackboard (2018). Blackboard Learn. https://www.blackboard.com/teaching-learning/ learning-management/blackboard-learn. https://doi.org/10.13021/g8460x

[33] Hussein, L.A., Hilmi, M.F. (2020). Cloud Computing Based E-learning in Malaysian Universities. International Journal of Emerging Technologies in Learning, 15(08): 4-21. https ://doi.org/10.3991/ijet.v15i08.11798

[34] Chipps, J., Kerr, J., Brysiewicz, P., Walters, F. (2015). A survey of University students' perceptions of learning management systems in a low-resource setting using a technology acceptance model. CIN: Computers, Informatics, Nursing, 33(2): 71-77. https://doi.org/ $\underline{10.1097 / \mathrm{cin} .0000000000000123}$ 
[35] Buyya, R., Srirama, S. N., Casale, G., Calheiros, R., Simmhan, Y., Varghese, B., Gelenbe, E., Javadi, B., Vaquero, L.M., Netto, M.A.S., Toosi, A.N., Rodriguez, M.A., Llorentem I.M., De Vimercati, S., Samarati, P., Milojičić, D.S., Varela, C.A., Bahsoon, R., De Assunção, M.D., Rana, O.F., ZhouW., Jin, H., Gentzsch, W., Zomaya, A.Y., Shen, H. (2018). A manifesto for future generation cloud computing: Research directions for the next decade. ACM computing surveys (CSUR), 51(5): 1-38. https://doi.org/10.1145/3241737

[36] Sultana, J., Mazmum, M.F., Nipa, N.J. (2017). Factors Affecting Cloud Computing Adoption in Higher Education in Bangladesh: A Case of University of Dhaka, Applied and Computational Mathematics, 6(3): 129-136. https://doi.org/10.11648/j.acm.20170603.11

[37] Adress, M.S., Omer, M.K., Sheta, O.E. (2016). Cloud Computing Adoption in the Higher Education (Sudan as a model): A SWOT Analysis. American Journal of Information Systems, Science and Education Publishing, 4(1): 7-10.

[38] Abdullahi, M.S.I., Salleh, N., Nordin, A., Alwan, A.A. (2018). Cloud-based learning system for improving students' programming skills and self-efficacy. Journal of Information and Communication Technology, 17(4): 629-651. https://doi.org/10.32890/jict2018.17.4.6

\section{Authors}

Wu Wei is a Master of engineering, Teacher at the School of Internet of Things Technology, Wuxi Institute of Technology, WuXi, China. Email: ipxplay@outlook. $\underline{\text { com }}$

Plakhtii Anastasiia Aleksandrovna is a PhD of Philological Sciences, Associate Professor of the Department of Foreign Languages, Prydniprovska State Academy of Civil Engineering and Architecture, Dnipro, Ukraine.

Article submitted 2020-09-15. Resubmitted 2020-12-07. Final acceptance 2020-12-07. Final version published as submitted by the authors. 